\title{
Natural products in a world out-of-balance
}

\author{
Geoffrey A. Cordell* and Michael D Colvard \\ University of Illinois at Chicago, Chicago, IL 60612, U.S.A. \\ E-mail: cordell@uic.edu
}

\begin{abstract}
Dedicated to Professor Atta-ur-Rahman, FRS in recognition of his outstanding contributions to natural products chemistry and society, locally and globally on the auspicious occasion of his $65^{\text {th }}$ birthday
\end{abstract}

\begin{abstract}
The natural world is careening out of balance in many different ways. Uncontrolled population growth, global warming, loss of biodiversity, and emerging new diseases, has fostered increasing drug resistance, dependence on synthetic chemicals and drugs, unregulated natural medicines, abused natural products, and the use of natural products as agents of mass intimidation, incapacitation, and death. This is not a sustainable situation for the planet.

Plants are the basis of the ecological homeostasis of Earth and its' living organisms, including the human species, and plant-based medicinal agents are used world-wide by humans and animals to treat a myriad of ailments. But, how will quality human health care, particularly in the form of locally sustainable medicinal agents, be delivered to a burgeoning global population?
\end{abstract}

Keywords: natural products; public health; traditional medicine; standardization

\section{Table of Contents}

Introduction

Developing a Future Vision

Conclusions

References 


\section{Introduction}

In a recent paper ${ }^{1,2}$, we discussed a diverse array of issues related to the future of that area of the sciences known as ethnopharmacology, the use of plants for medicinal purposes by indigenous groups. In a separate paper, one of $\mathrm{us}^{3}$ presented some of the background with respect to the global issues of the use of traditional medicines, and how a new scientific basis was needed for plants to contribute in an optimal manner to enhancing health care for the majority of the world's population. This brief presentation may be viewed as an amalgam and an enhancement of those three papers and several others ${ }^{4-10}$. Although repeated calls for a new agenda for natural products in the world, for example the UN Millennium Ecosystem Assessment ${ }^{11}$ have the foresight to build a new agenda with far-reaching policies to maintain diversity in the world, most of these calls have gone unheeded.. The question therefore remains. "When the world population reaches 8,9 , and 10 billion, what will be the sources of the medicinal compounds and agents for the world's most prevalent diseases?" This would appear to be a foundational question that any government would desire to address, since a stable and healthy population fosters and an environment that fosters a stable government. This question involves fundamental financial and strategic issues for the governments and their public health care systems extant in various countries around the planet as they fulfill their responsibilities for their respective peoples. Moreover, it would seem to be an opportunity for the Traditional Medicine Programme of the World Health Organization to lead a discussion of this critical public health question.

At the same time, as we examine some of the potential sources of health beneficent drugs for the future, many populations in the world are facing what can only be described as the "dark side" of biologically active natural products. Namely, their use in weapon form for mass destruction, mass incapacitation, and mass intimidation. Further, there is the increasing production and use of natural illicit drugs which pervades the very basis of so many societies.

So there is the crux of the issue....... on one side, the incredible health benefits that have, do, will, and must, accrue to the human race as a result of treatment with constituents derived from plants and other natural (marine, fungal, bacterial, and animal) sources. On the other side, there are the terrible detrimental human and social aspects of the abuse of natural drugs recreationally, and those used as an integral part of terrorist or subversive tactics by militant groups. However, overarching this scenario is an even bleaker reality, from which natural product scientists may be challenged in the future to perform the impossible.

The profound wisdom of Saint Hildegard of Bingen (12 $2^{\text {th }}$ cent.), Emerson $\left(19^{\text {th }}\right.$ cent $)$, and Lovelock $\left(20^{\text {th }}\right.$ cent $)$ coalesce in reminding us that as a human race we are totally dependent on our relationship with Nature and its' biodiversity. Many political, social, and business leaders around the world either have never been made aware of this fact, have forgotten, or have chosen to ignore, this fundamental aspect of the survival of the human species. One of our challenges as natural product scientists is to enlighten that view.

Plants are used by humans in many ways, including perfumes, cosmetics, flavors, spices, paper, construction materials, and food stuffs. The fundamental processes by which our bodies 
are able to function depends on natural products and their metabolic breakdown to provide us with energy, maintain homeostasis, and restore our daily depletion. Can we anticipate that these needs will continue to be met for a burgeoning population? Significantly, in April 2005, the Millennium Ecosystem Assessment carried out by the United Nations ${ }^{11}$ indicated that "...the ability of ecosystems to sustain future generations can no longer be taken for granted". There seems to be a perception and long-held assumption by many governments and leaders that no matter how many we are on this Earth or what we do to the Earth, that it will still provide for us. We are so very, very wrong. We have tipped the scale of population vs. resources, probably for all time, and the balance of resources and their use is no longer in our favor. This paper is not about finding a way back to restoring that balance, for that is likely impossible. Rather, it indicates the very serious consequences of what we are doing currently with respect to a very unsettling future, and suggests that in one area at least, natural medicinal agents, there could be resources available for the future, if we act now. The United States Census Bureau ${ }^{12}$ has identified unchecked population growth as a significant global problem. It is the "elephant" in the room that whole religions, governments, and multitudes of otherwise responsible international agencies appear extremely reluctant to discuss. One is led to speculate that many have not seen the population projections for the next 30 years $^{12}$. If they had, one would expect policy statements that presage the concern that this is the core issue for humanity and simply must be addressed for humanity to survive with any semblance of a reasonable life.

There are many aspects and examples of how humans have shifted culturally to a world in which we are now disassociated, detached, out-of-sync, and out of balance with nature and its resources. When one looks solely in the area of health, they include: the exploding global population $^{13}$, the pantropical deforestation ${ }^{14}$, the dramatic increase in fossil fuel use, and the resultant warming of the air and the oceans, the emergence (almost annually!) of new, deadly, and therapeutically demanding global diseases, the disparity between the efforts towards drug discovery for the health care needs of the North vs. those needs for the South, the stunning inefficiency of the drug discovery process, the dramatic increase of drug resistance for many of the major global diseases, and the use of unregulated traditional medicines in the health systems of the majority of the population of the world. The abuse of illicit natural drugs and the potential and real use of natural products as WMDs and WMIs should also be added here.

As indicated ${ }^{1}$, we have acquired an insatiable dependence on non-renewable sources, particularly oil and coal, for many of the fundamentals of life, including plastics, textiles, transportation, and medicinal agents. In reality, Nature affords us access to these basic materials only once in the history of humankind.....yet nearly all of us act as though these energy and raw material supplies were limitless. We are living in the dense fogs of illusion and fantasy, befuddled by the grandeur of our lives into thinking that 10, 20, or 30 years from now we can lead an even better "life". This illusory bubble of "permanence", that the resources will always be there, is a pervasive fiction. It is about to burst. Let us be very, very clear, again, "...the ability of ecosystems to sustain future generations can no longer be taken for granted" "11. While we may think (as we are told by most of our governments) that we are fighting wars against 
cancer, against terrorism, against drugs, or against some other real or mythical foe, these are merely small battles......for we are truly in a much more deadly conflict......one in which the very survival of the human species is at the epicenter of the battle. Visionary (the "smart") countries will be those which can see, accept, and take up these challenges for humankind, and not be distracted utilizing their critical fiscal resources for the lesser "battles".

In spite of the pervasive economic notion that technology will allow further production gains, accessible global oil production is likely to peak within 2 years (by 2007-2008). By 2020 the Middle East will control $83 \%$ of global oil supplies, and by 2070 , there may be no more costeffective oil supplies available ${ }^{15-17}$. About $75 \%$ of the existing prescription drugs in the United States are synthetic ${ }^{18,19}$, and for the remaining $25 \%$ derived from nature, they too rely on organic solvents for their extraction and purification. So let us ask a fundamental question....from where will the medicinal agents of the future (say 2025, 2040, 2060) be derived as living biomaterials are depleted and the global competition for oil increases on a daily basis? What should we be doing now to prepare for these scenarios? Where is the vision for global health care that will face these challenges in a constructive, rational, and meaningful way? For failure to come to terms with these realities will inexorably undermine global health for the majority of the world. How will this message of deep concern be transmitted effectively in time for a reasoned response?

One of the major issues which all natural product scientists must face is one of "voice". We have not presented a consolidated "voice" able to contribute to defining the global priorities for which we are the content experts. We naively think that so long as our grants to study this plant or that fungus or that marine organism for its effect against a particular disease (say cancer) is funded, all is well in the world (or at least our world!). We are wrong, for in reality our contributions make little impact on global health care, have little influence on delivered bioscience based medical and dental care, and thus are not relevant to public health or government policy makers. We have a significant responsibility to become substantially more socially aware, by contributing to and setting the public health agenda. We must engage in the current global public health dialogue centered on access to medicines and primary care medicine standards. We must stop contributing individually to a burgeoning (and increasingly irrelevant) literature, but instead publish by defining how traditional medicines contribute to the established bio-science medical systems within national or international health care programs for the development of improved health care systems around the world. We must begin to assume a much more aggressive role, collaborating with a broad range of political, public health, and medical professionals to address, scientifically and from a regulatory perspective, what are the local priority health issues and what sustainable resources will be used to address them.

There is no shortage of global and local health issues to be considered for our attention. Diseases such as AIDS, tuberculosis, diarrheal diseases, malaria, and hepatitis B are responsible for over 9 million deaths per year. Tobacco-induced diseases (cancer and respiratory) account or an additional 3.5 million deaths world-wide. Additionally, there are major tropical diseases with high incidence, but which are not lethal; examples include leshmaniasis, thalassemia, hepatitis C, 
and leprosy.

At the same time as the search for natural products which can improve health care continues in various forms around the world (vide infra), it is important to recognize that other natural products, because of their potent biological responses, are undermining the very core of society in many countries of the world, while also serving as important chemotherapeutic agents. Two of these entities are the alkaloids morphine from Papaver somniferum (Papaveraceae) and cocaine from Erythroxylum coca (Erythroxylaceae). For these entities, the research directions over the years have focused on developing derivatives of morphine and codeine which potentiate the analgesic and antitussive activities (e.g. demorol and dextromethorphan), and on developing anesthetic derivatives related to cocaine (e.g. lidocaine and procaine). At the same time, creativity has been required to develop innovative detection methods for these alkaloids and their derivatives as the need to control illicit importation has increased.

For over $64 \%$ of the global population, plants are used in traditional systems of medicine as a primary source of health care, where they are usually prescribed by a local healer and paid for directly by the patient ${ }^{20}$. In the countries of the developed world, phytotherapeuticals, dietary supplements, and herbal products are used, often chronically, as lifestyle prophylactic agents, typically on the basis of self-prognosis, and without medical advice or the possibility of health insurance re-imbursement. There is a curious connection between these two disparate groups of patients which encapsulates the failure of the natural product sciences in public health. It is that in both instances the patient is using substantially or completely unregulated products, where the safety and efficacy of the purchased product are essentially unknown. In reality, this represents another abuse of natural products in health care, where the motives are financial and not truly for the benefit of the patient. Some very similar ethical issues arise in the marketing of drugs by the big pharmaceutical companies, as we shall now see.

One of the core activities of a major pharmaceutical company is the development of a new prescription product which will make money for the company and for the companies shareholders for many years, thereby permitting reinvestment in new research, leading to new prescription products, etc., etc. For the past forty years or so this cycle of research, development, and marketing activity seemed to be working very well, as typically, the most profitable market sector was big pharma ${ }^{23,25}$. Numerous, so-called block-buster, drugs were introduced and the quality of health care as result of these new product introductions had a dramatic effect on disease mitigation and life prolongation. Yet these companies have done very little to address the treatment of global health diseases, for only about $1 \%$ of the 868 new products introduced in the period 1981 to 2002 has been for the diseases of the developing world ${ }^{21}$.

In the past three years, and as the number of major pharmaceutical companies has shrunk, as research programs have consolidated, as more research has been out-sourced ${ }^{22,23}$, as new chemical entities have been licenced in, and as the costs from bench to market and beyond have increased to at least $\$ 800$ million/drug ${ }^{24,25}$, the relationship between big pharma and health care has reached a crisis point. This estimate, which may be as high as $\$ 1.7$ billion $^{23}$, is not an individual cost for drug development, but an amortized cost over the life of the research program 
for all drug discovery, development, and post-approval marketing and sales costs ${ }^{23}$. Of particular concern has been the stunning increase in direct consumer marketing in the past ten years ${ }^{26}$.

The technologies of combinatorial chemistry have not yielded the promised new drugs in a timely, more efficient manner ${ }^{27}$, the heavily-marketed drugs that are introduced are often for benign diseases ${ }^{23}$ where both prescription charges and re-imbursement rates are high, and the public trust in big pharma as a result of unethical withholding of unfavorable clinical data prior to or post introduction has led to important clinical entities being withdrawn and voluminous litigation ensuing ${ }^{23}$. As safety standards, and therefore costs, to introduce new entities increases, even fewer companies will be fiscally able to introduce new entities. Failure rates in Phase III trials have risen dramatically, and thus fewer drugs are now being introduced annually in the $\mathrm{US}^{27}$, and yet the waiting time for approval is again on the rise. Another significant complication is that with the prospect of individualized therapeutic regimens on the immediate horizon, it is not clear how these will be approved by regulatory bodies such as the US Food and Drug Administration. So what is the vision for natural products in health care that we need to be considering for the next 20,30,50 years and beyond? Recall that we have a burgeoning population, a technological capacity for discovery that is excellent, and the likelihood of increasing killer diseases, while at the same time oil supplies are diminishing, as are all forms of plant and animal biodiversity. Indeed, a recent estimate indicates that between $39-43 \%$ of endemic plant and vertebrate animal species in 25 ecological hotspots would become extinct by $2100^{28}$.

\section{Developing a future vision}

It is well established that compounds from plants have been, and are, important in health care systems as prescription, over the counter, and phytotherapeutical products and traditional medicines ${ }^{19,29}$. For the future, one can envisage that as the cost of synthetic drugs rises and health insurance companies retrench to even smaller, cheaper drug formularies, efforts towards developing natural based pharmaceutical entities will actually increase. But this will happen predominantly for the population of the developed world. In the developing world, there will be even more limited access to new drug discoveries, and burgeoning populations will increasingly rely on improved natural products based on traditional medicines. The question of who pays for these health care developments is obviously of critical importance, but is beyond the scope of the authors. What we can address though are some of the public health and scientific factors that will enter into the discussion of any future vision.

We are moving towards a world, even in the most developed countries, where only a select few will have affordable access to health care. Already in the United States there are almost 12 million children under 18 who do not have health insurance ${ }^{30}$. Pragmatically, the big pharmaceutical companies will not be developing drugs for populations who collectively cannot, through sales or insurance coverage, return in a finite (2-4 year) period the costs of putting that 
individual product on the market.

Traditional medicines, and even natural product extracts are not a part of the strategy for the basic discovery of "hits" in the major pharmaceutical companies ${ }^{21}$. Natural products are only occasionally included as individual entities in the high-throughput screening of compound libraries. And the many cogent reasons for this are outlined later in this article, and have also been discussed elsewhere ${ }^{5,6,8,9}$.

The pharmaceutical companies responsible for these screening programs are not based in the developing world, and the products that come out of such programs are not likely to be marketed in developing countries, unless the unit costs are reasonable. As a result, it is important to realize that most of the population of the world will have to be responsible for the preparation and distribution of their own pharmaceutical and traditional medicinal products for many global and local disease states through local research discovery and development programs. This is a critical facet of public health care for the developing world into the foreseeable future and bears repeating in an alternative manner.

For the developing world, it will be up to government agencies, in concert with the local pharmaceutical infrastructure and the academic institutions to develop and enact plans for quality medicinal agents for their future health care systems. The role of imported prescription, OTC, and medicinal plant drugs, relative to that of the corresponding, internally produced, medicinal agents will clearly center on local capacity ${ }^{2}$. In the absence of an assured, continuing funding base, that capacity will fluctuate, but hopefully evolve over time. Within a developing country one can easily envisage multiple layers of drug access, depending on cost and infrastructure. The majority of the population of the world though will clearly be relying on a second, third, or perhaps even fourth tier of medicinal agents. Few governments in the world are yet aware of this reality, and therefore are not planning for the drug aspects of their prospective health care systems in an appropriate manner. We believe it is essential that this public health disparity, and the science-based approach that will be required to sustain even minimum standards of quality control for the variety of drugs for a burgeoning population, be addressed as a matter of high priority.

Before moving to a more detailed vision of the ways in which natural products research will need to evolve in the next ten years or so, we will address the issue of scientific responsibility. As individuals contributing to a scientific area, and collectively as scientists, we often are so deeply focused on the "now"; on whether we can determine a particular structure, or whether we can interpret the data from a bioassay, that we lose sight of a bigger picture. What are the health issues that need to be addressed as specifically local issues (e.g. leshmaniasis) compared with those which are of global significance and which are already being addressed widely with substantial government and corporate funding (e.g. cancer)?

There are several major areas where biologically active natural products can contribute to the enhancement of the human experience; these include: i) discovery for single agent drugs, drug auxiliaries, or multi-drug resistant agents, ii) in the validation of effective, standardized and safe traditional medicines and phytotherapeuticals, iii) in health beneficent nutraceuticals and 
cosmeceuticals, iv) in insecticides and herbicides, and v) in the detection of detrimental natural products being used as weapons of mass destruction, mass incapacitation, or mass intimidation. Individual countries will eventually have to make difficult choices for the investment for their research dollars. For example, is it an appropriate use of precious resources for medicinal plants in Kafkastan to be evaluated against a single human cancer cell line such as KB, when the dominant local disease is schistosomiasis, for which there are no imported drugs available?

The question is frequently asked as to why there is the need for continued drug discovery for new single agent medications. In itself, this is a complex and lengthy issue. Simply put from a global perspective, there remain a plethora of diseases for which there are no drugs available. In addition, the development of knowledge regarding the human genome establishes a situation where the promise of more targeted gene therapy might provide both enhanced treatment and a minimum of side effects. There is an increasing number of infectious diseases which continue to loom over the human population because drugs which once were effective now have no, or very limited use, as strains of organisms, including fungi, bacteria and parasites, develop resistance to the front-line and the second-tier drugs ${ }^{31}$.

We have seen previously how almost every year a new global disease is threatening humankind. At the moment it is the H5N1 avian flu virus, as it is apparently carried around the world by migratory birds which then infect local captive birds (chickens, ducks, etc) used as food. As of Summer 2006, the outbreak had taken the lives of about 138 people ${ }^{32}$, compared with the SARS epidemic of 2003/2004 which claimed about 774 people $^{33}$. While these numbers are still small, the danger arising from the potential for mutations of the virus to become less susceptible to existing drugs, for the vaccines to be ineffective against mutated strains, for the transmission to become direct human to human (as in TB transmission), and for an inadequate supply of therapeutic agents, is generating a wide range of very serious public health and economic concerns.

As indicated previously, there is substantial evidence that the cost of developing, marketing, and conducting post-marketing surveillance on a single agent new drug is in the $\$ 800$ - 1,700 million ${ }^{23,24,27}$ range. Only a handful of countries have indigenous pharmaceutical companies and health care systems which can support such integrated product development. This is not a sustainable situation for the developed world, and the less-developed world must understand that their medicinal agents must come from a different discovery pathway than that of the US and Europe. We know from a long, broad, and deep historical perspective that natural products as single agents have had a dramatic impact on health care. One of the discussions that needs to occur locally and globally is whether that role has ended or whether it is ongoing. Our bias of course is that natural products and/or their modified derivatives, as single agent drugs, must become an integral part, once again, of the major pharmaceutical company discovery strategy, albeit on different terms than in the past. For less developed nations, their governments must examine how they can effect sustainable medicinal agent acquisition and delivery programs $^{2}$ which are cost effective through either the development of known natural products or the discovery of new agents which are both cheaper to develop, and cheaper to market than those 
entering their local market from the developed world. What are the arguments which oppose such long-term strategies? What are the reasonable alternatives that we face now?

We have seen that oil prices, and therefore the prices of chemical reagents and solvents will increase as the global competition for oil intensifies. As the solar battery or the wind pump may be an alternative energy source for electrical power for houses, and for transportation, natural products are the alternative source for drugs when synthetic chemical and solvent prices drive the cost of drugs to levels where only the heavily insured rich of the world can afford them. Other industries whose interests focus on textiles, energy, and plastics are already looking at plants as a sustainable option for the future of their raw materials. It is time for the health care industry, particularly that sector focused on the provision of medicinal agents, to think in terms of renewable sources ${ }^{2}$; to think in terms of medicinal agents as a sustainable commodity which, in their provision to the global population, does not deplete the resources of the planet.

Based on the absence of discourse in the literature, one obtains the very strong impression that the global pharmaceutical industry has not considered the origin of medicinal agents 15-20 or 30 years from now ${ }^{23}$. There is a continuing assumption that the oil and the coal, which are the foundational basis for synthetic drugs, are endless chemical resources, or that somehow the genomics/proteomics revolution will yield all of the drugs needed for the future. They are wrong, very wrong, and to not recognize that fundamental reality is to be living in the golden dome similar to that which formerly surrounded antibiotic therapy. The short term focus of companies on the drug pipeline for the next two, or five years, which keeps shareholders bouyant and the stock rising, is closing off a discussion of another elephant which is sitting in the corner of the room and being ignored.

For the sake of global health care we cannot ignore that elephant. Not only is it too big, and too powerful, but elephants live a long time and have good memories. They remember the time before medicinal chemistry and computer-aided drug design and combinatorial chemistry. They remember when the only source of medicinal agents was a natural one. They are also smart enough to know that when resources become limited, alternative pathways are essential for survival, a new fertile ground is needed for the group to survive, and new strategies for the journey to reach there must be deployed. This is the future of natural products in the $21^{\text {st }}$ century. It will be a very exciting one, if we are prepared to accept the realities of the new challenges that face us.

Natural products, as shown by the NCI group ${ }^{21,34}$, have made significant contributions to several therapeutic areas in the past 25 years. Given the limited number of drug discovery research programs in which natural products have fully participated, this outcome is both surprising and disturbing. Pharmaceutical industry has consistently voided aspects of natural product research indicating several reasons of variable cogency: i) assays cannot be maintained while bioactivity-directed fractionation programs isolate an active isolate from an active extract, ii) known active compounds are frequently obtained when active fractions are separated, iii) active extracts often yield inactive fractions, iv) yields of active compounds are frequently low and do not permit additional testing, and v) it takes too long to recollect a known active plant in 
adequate amount for large scale work up for further biological and pharmacological screening. These are serious issues for natural product scientists to ponder and overcome if they wish to see natural products contribute to the drug discovery plans of the major pharmaceutical companies. Perhaps though there are some other avenues for improving health care involving natural products which are, globally, more significant. As we shall see, there are also a number of strategies which can be applied in order enhance the role of natural products in health care, even in the major pharmaceutical companies.

The contributions of natural products to health care are well-known on a daily basis, albeit substantially unappreciated by the pharmaceutical industry, by physicians, and by patients. One of our goals, as scientists and educators must be to raise awareness in each of these communities regarding those current contributions. We must also recognize that there are new opportunities arising for the discovery of medicinal agents. Two simple examples will illustrate how, without much effort, a whole different dimension of natural products discovery for health care might be envisaged. These examples are alkaloids ${ }^{35}$ and ethnopharmacology ${ }^{1}$.

The contemporary use of approximately $74 \%$ of the natural product prescription drugs in the United States corresponds to the original ethnomedical use of the crude drug preparation ${ }^{19}$. The NAPRALERT database contains ethnomedical records on approximately 14,300 (about $5.2 \%$ ) of known plants, but of these, only about $40 \%$ have thus far been subjected to chemical or biological evaluation ${ }^{1}$. It is also clear that this is only a very partial story since there is still a great deal of ethnomedical information which has never been collected and presented (vide infra). It is an incredible discovery opportunity which demands a broad-based response.

For the alkaloids, the situation is even more disturbing ${ }^{35}$. While alkaloids comprise about $15.2 \%$ of the structures of known natural products, they provide $46 \%$ of the plant-derived pharmaceuticals. Alternatively, one can say that simply by studying the biological activities of alkaloids one is three times more likely to find a single agent drug. In addition, for those alkaloids which have been subjected to bioassays in more than 20 biological categories over 33\% are single agent drugs. Yet, very distressingly, $76 \%$ of all known alkaloids have never been tested in a single bioassay ${ }^{35}$. The same is probably true of many natural product compound groups such as flavonoids, coumarins, lignans, steroids, and acetogenins. This situation arose because for so many years there was a great chasm between the efforts of the chemist and the efforts of the biologist. The chemist was isolating compounds, the biologist was looking at the actions of known compounds, and neither was talking to each other. Fortunately, at most academic institutions now, the level of collaboration and the sense of responsibility to examine natural product isolates for at least some potential biological activity is a reality. The issues go substantially beyond local academies and collaboration though, they go to the core of rational, targeted research funding.

Where will the nations of the South turn for their health care needs if, as projected above, the medicinal agents from the North are not available or are too costly? If, as indicated above, the answer is to be based on traditional medicines or purified natural products then some major regulatory and infrastructure improvements are needed. Current public health policies regarding 
natural products and traditional medicines require immediate review and overhaul in order to protect the patient and enhance health care. The contemporary situation on a global basis is scandalous and is not serving the patient. We already know that traditional medicines are a fundamental aspect of basic health care needs globally. But the scientific evidence for their safety and efficacy is lacking, and most of the products, whether they are single agents or mixed preparations of plant materials, are largely unregulated. There is inadequate oversight, legal or voluntary, with respect to contamination of the plants, either through pesticides, insecticides, and herbicides, or through adulteration to enhance efficacy. These and other concerns present a potentially very serious health hazard, and from an ethical, public health, and scientific perspective are indicative of an unacceptable situation.

The need for a deeper reverence for the natural environment has been long recognized. "All nature is at the disposal of humankind. We are to work with it. For without it, we cannot survive." This quote of Saint Hildegarde of Bingen from the 12th Century, cited by Matthew Fox in Original Blessing, is an ancestral thought to the Gaia hypothesis ${ }^{36}$. As Lovelock opined, it is not that we just work with it (nature), we are it. We are just one part of the biological system, our parent body, called Earth. As we damage and do not heal the Earth, we are damaging, irreparably, several parts of our own body. Through deforestation, coral reef damage, global warming, the impending water crisis, and the failure to control population, we are facing a situation where a major natural correction in the balance of the Earth will have to be effected, irrespective of what actions we might think we are capable of to "control" nature for our whimsical needs.

"If you are on the fifth step and you think you are too high, you will never make it to the sixth step." (Ajahn Chah, A Still Forest Pool)

Do we believe that we are on the fifth step already? Do we believe that we are at the zenith of natural products in drug discovery, or in the optimum use of plants and their derived preparations for the health of the global population? Do we believe that there are no new strategies to be envisioned, developed, and applied? If we do, then we are definitely failing future generations. ALWAYS, we must be considering the need for a new vision for natural products in health care for the future health of the planet, including it's human, plant, and diverse animal populations. As technology continues to evolve, it is our challenge to consider those developments and incorporate them fully into a continually evolving mission. Since one of us first considered this topic several years ago $^{7}$, the need for an evolving vision has grown even more ineluctable.

As indicated previously, the most significant (and most frightening!!) issue facing our survival on Earth is that of a population out of control. A look at the website (www.ibiblio.org/lunarbin/worldpop) where the global population clock is displayed, reminds us that each second the net population of Earth increases by three people. While it is easy to cast blame on various groups for failing to see that they have a great responsibility in promoting responsible practices for conception, the concerns must transcend religious and political thinking. We cannot begin to cope with the level of poverty in the world today, let alone support 
a population of 10 billion people by 2035 . It has already been estimated that to support the current population of Earth in the "style" of the North would take the resources of four additional Earths $^{37}$. We must first recognize a fundamental global requirement for the survival of our existing, let alone our burgeoning population; a deep and abiding commitment to the conservation of natural products from the marine and terrestrial environments, for it is those resources which must continue to contribute to health care maintenance and food science, as other resources are depleted.

Past scientific practices have not worked to optimize the potential for natural products in health care ${ }^{5,7}$. Thus, we must create a new vision for natural medicinal agents which embraces intellectual property, biology, chemistry, information systems, technology, and biotechnology as they apply to the discovery and development of biologically significant natural products. It must be understood that every contemporary natural product medicinal agent practice needs to be reexamined and reconsidered. The status quo is simply no longer applicable. For traditional medicines and phytotherapeuticals we are on the second step (at best!) and need to reach the fifth. Perhaps then, we will be in a position to contemplate the sixth and the seventh. A number of the aspects of this vision have been described previously ${ }^{1,2,6,7,9,10}$, thus only a very abbreviated summary will be presented here.

We are seeing a steady increase in the automation of the screening of samples for biological activity and in the deployment of those assays in a laboratory setting. The development of nanotechnologies which can assist in the miniaturization of this process is ongoing and we are approaching a greater understanding of the genetic impact of a given medicinal agent across diverse gene systems. In the future, for the North, this will inevitably lead to a tailored health care approach where individualized diagnosis can lead to a correspondingly personalized therapy.

For those natural products where there is a need to enhance availability and lower cost, we will see the results of the current on-going efforts to examine the genetics of plant and fungal biosynthesis. There is a need to place these processes under definitive control so that the biological variability currently inherent in natural product production can be mitigated. Within each organism producing secondary metabolites there are molecular "switches", transcription factors, which serve to initiate, control the volume, and terminate each, or a series of, metabolic steps. One of the very fertile areas for the future will be enhancing our understanding of such processes, so that the production of critically important natural medicinal agents, such as morphine and vincristine, can be optimized. There is substantial effort underway to produce a number of vaccines which, if successfully deployed, might enhance human health in selected disease areas. However, it will not be possible to innoculate the population in all of the malariainfested areas of the world with a vaccine using current technologies. Consequently, the use of either an oral vaccine or a secondary agent, such as a foodstuff (rice, taro, potato, etc), will be critical.

There is a need for a new vision for natural products chemistry. We have already seen how the pharmaceutical industry is no longer evaluating plant extracts for their biological potential, 
and have indicated the background causes for this situation. If, and it is a big if, we wish to see plants and the marine environment contributing to this contemporary discovery pathway, we must re-orient our strategies to improve the isolation of novel, biologically active, natural products from complex matrices ${ }^{38,39}$. Currently, the discovery of medicinal agents is a very inefficient process, whether the source is synthetic through combinatorial chemistry or the screening of vast libraries of compounds, or natural through the collection of thousands of plant samples.....the yield to find a single compound of even moderately interesting biological activity is extremely low. From several hundred random samples, maybe one will have a truly interesting biological activity. How can this situation be changed? It is clearly no longer appropriate to found a discovery program on field-based collection wherein samples are returned to a laboratory, extracted with several solvents of differing polarities, and samples of each of these extracts evaluated in a particular bioassay. Alternative strategies in which plant materials are evaluated in the field for a diverse array of biological responses and preliminary chemical analysis conducted are urgently needed.

Pharmaceutical companies, in the earliest stages of drug discovery, consider it important to bring as many compounds as possible to a particular bioassay for evaluation. Natural product chemistry has lagged behind the synthetic chemical sciences in addressing these needs. So how does one enhance natural product structure diversity? There are at least five methods, including, i) combinatorial chemistry on strategic natural products, such as certain alkaloids, steroids, diterpenes, and lignans, ii) combinatorial biosynthesis, whereby shifting the gene sequence causes the production of previously unknown metabolites, iii) the use of microbial or isolated, stabilized enzyme systems to produce changes in the structures of specific biologically active natural products without prejudice as to outcome, iv) the potentiation of the genes of biosynthesis to realize the full metabolic capability of a given organism, and v) new sources of potential secondary metabolites, such as plant-associated, uniquely resourced, or difficult to grow fungi and bacteria.

For countries whose pharmaceutical strategy includes the partial or complete synthesis of compounds (synthetic or natural), the cost of reagents for standard organic transformations is very high. For companies in the developed world, there is now a very dire need to move major industrial processes to a more "green", environmentally benign, cost effective status. The use of renewable, or at least easily sustainable, chemical agents for the conduct of major organic transformations could have a significant impact on the economics of such processes. Several years ago, the use of a preparation derived from carrots (Daucus carota) was described which was capable of the reduction of carbonyl groups in modest yield and with a very good degree of enantioselectivity $^{40}$. More recent studies have shown the selective reduction of a wide range of ketones and aldehydes in $>96 \%$ yield and $>97 \%$ ee using preparations of selected vegetables ${ }^{41}$. If these studies can be enhanced and diversified to other, basic organic chemistry reactions (e.g., stereospecific oxidations and reductions) the need for expensive chemical reagents to be imported into less-developed countries at exorbitant cost will be diminished.

It is a slight overstatement, but we are all patients taking phytotherapeuticals. Note that we 
make the clear distinction between a consumer and a patient. Many authors, including one of us (GAC), have previously, erroneously, referred to persons taking such preparations as "consumers". It is important to recognize that when we use the term "consumer" we are implying that such products are in the same category as candy, or a sandwich, or a used car. They are not, they are potentially very powerful biological agents. This situation has occurred because there is an incompatibility in how traditional medicines are valued in comparison with single agent drugs. While this has occurred in part because of the resistance of allopathic physicians to see ANY value in many of these products, we natural product scientists are also to blame. For the fact is that the science associated with single agent drugs is valued (appropriately so) substantially above the science applied to a traditional medicine. This involuntarily places traditional medicines at a lower scientific level. Consequently, these products unconsciously become second (or third) class drugs in the eyes of health care practitioners and patients. The fact that many of these preparations have been used for thousands of years is irrelevant. At that the same time, this devaluation also fails to recognize that these materials frequently do contain some very potent biological agents, and thus, in the same way that allopathic drugs should not be abused, so phytotherapeutical preparations must be regarded with profound biological respect.

It is for this reason, that we must regard ourselves as patients when we take these products, for there is another medicinal aspect as to why we choose, voluntarily, and frequently without medical advice, to take these products. Namely, that we expect, based on our own acquired knowledge, that like other preparations containing a potent biological agent, such as coffee, tea, or even a cigaret, that they will "work". We anticipate that the desired biological response will result. That is a profound trust.....unless labeled that the coffee is "decaffeinated", the expectation (the trust) is that the coffee beans contain an adequate amount of caffeine per cup to produce a desired effect of stimulating physical and mental activity.

In many places in the world, car dealers now are required to advertise a used car with the year of the car, an accurate mileage, the number of owners, when services were completed, and whether that car has been in a major accident or flood. Many used car dealers will provide additional warranties with such vehicles attesting to 100 or 120 point checklists which the car has passed. How does this compare with the current checklist for a traditional medicine or a dietary supplement?

In most parts of the world, there is not even a legal requirement that the correct part of the correct plant be supplied. In the United States, that is the minimum standard, and that there is no medical claim being made. There are no requirements that relate to a demonstration of botanical authenticity, of chemical content, of in vitro or in vivo biological effectiveness. There is no indication of how long the product has been demonstrated to retain effectiveness, nor whether there are any known or possible contraindications with other phytotherapeutical or allopathic medicinal agents. Thus, for patients in almost every country in the world taking a phytotherapeutical product they have no idea and no assurance as to what they are buying and using for self-medication.

The fact is that we are more protected as consumers when buying a used car, than as 
patients when purchasing a phytotherapeutical. From any rational public health perspective, this can generously be described as absurd. We, as patients and as scientists, deserve, and must be demanding much, much more. For this is NOT an acceptable public health policy situation enhanced, evidence-based, quality control of medicinal plants is a global issue. Failure to address this critical issue at the political, economic, and scientific levels seriously undermines the credibility of Natural Products Research. Therein lie a veritable plethora of opportunities for the improvement of public health.

It is indeed unfortunate that the World Health Organization Traditional Medicine Programme has not assumed this responsibility and seized the opportunity. Providing guidelines for the cultivation of medicinal plants, or a select few monographs, or studying the global regulatory status, does not address the fundamental scientific and regulatory issues which are at the core of this appalling public health care situation. In this absence of global leadership we are left with only the voices of a few scientists who are warning of the impending crisis as the population of the world grows and the reliance on medicinal plants inexorably expands.

One of the potentially most significant activities that scientific societies can promote, as the experts in the field, is the standards for the field at the national and international levels. While there are indeed some regions in the world where this has occurred, scientific societies have been notoriously weak in this area, with researchers tending to pay attention to their own funded research and reporting on those results, rather than pushing legislatures and government agencies to provide the money to do the basic, applied, and clinical research which will improve public health. For example, the amount of money spent by the National Center for Complementary and Alternative Medicine (NCCAM) on research in 2005 was \$ 121 million (this the total NCCAM budget). Compare this with an overall NIH budget of $\$ 27,749$ million, and you can see the picture.

The quality control issues regarding phytotherapeuticals were, for many years, a "chicken" and "egg" situation which resulted in balancing regulations versus science. Was the science adequate to define the needed regulations? Did the science stimulate the regulations or the regulations the science? Those questions are now clarified; it is the science which can (indeed must) lead to safe and effective products, and thus improved health care. Our responsibilities as scientists are therefore to: i) enhance the botanical, chemical, and biological science behind each preparation, and ii) develop harmonious regulations for traditional medicines and phytotherapeutical preparations.

A proposal and flow chart for the development of traditional medicines has been made previously ${ }^{2,9}$, and will not be repeated in detail here. In summary, it is a vision for the quality control of medicinal plants for patients and focuses on an integrated technological approach for the botany, chemistry, and biology associated with a demonstration of reproducible effectiveness and standardization. For no plant used as a phytotherapeutical has this level of quality control been achieved. However, it is reasonable to expect that this is the "sixth step". It represents an array of technological standards which must be considered as vital for there to be a wider acceptance of medicinal plants as a standard of care, and for phytotherapeuticals to be seriously 
considered as important biological agents on a reproducible basis.

\section{Conclusions}

"Natural products are safe" is a frequently heard mantra in the traditional medicine, phytotherapeutical, and dietary supplement industries around the world. Perhaps as a result, both patients and physicians, as well as the appropriate regulatory authorities have been lulled into a sense of inactivity. A sense that "if it ain't broke, don't fix it." Unfortunately, it is "broke". It is broke because it was never "fixed". As a result of inactivity, there never was, anywhere in the world, an effective system for the quality control of these sometimes potent, sometimes toxic, traditional medicines and phytotherapeuticals. Yes, there have been attempts to bring preliminary measures of quality control to certain products around the world, and probably the German Commission E monographs represent a higher level of applied plant sciences than anywhere else in the world. But this is a global public health situation, peoples lives, their health expectations, typically their own financial resources, and most often, their own background experience, reading or self-knowledge from traditional or contemporary resources, are the basis for a decision to self-medicate.

We scientists who profess knowledge and expertise, who have studied these wondrous factories of secondary metabolism, who have isolated, determined the enchanting molecular structures of some of these bioactive agents, and who have examined the actions at the molecular, cellular, animal, and human level of a limited number of these agents; we "experts". We now have an added responsibility. We must act to promote the regulation of traditional medicines and phytotherapeuticals on solid, evidence-based science. It is indeed the time to say, enough is enough. Morally, as scientists, we should no longer support, through inaction, the level of blatant and inexcusable fraud that is evident today in the phytotherapeutical marketplace. It is a time to develop, within our learned and professional groups, the wisdom to promote the idea of a guaranteed safe and effective traditional medicine or phytotherapeutical product. A product on which the patient can rely for the duration, be that one week, one month, one year, or chronically. A product which has validity, irrespective of where or when bought, independent of the manufacturer, and wherever in the world it is being sold. It is a minimum expectation, yet stunningly, it remains a far off vision. Only we, the experts, can create those visions, maintain them through changing sciences and technologies, and see them through to a constant reality. It should be an integral, and essential, aspect of own creative, scientific, and personal growth.

Let's be very clear about this scenario, we are not (and cannot be) doing this for ourselves. We are doing it, and must continue to push for evolution of the science and technology associated in this area, because we have a very deep obligation to our future generations. Their expectation is that they will inherit a world where basic public health issues, such as the optimum quality of materials applied for the purpose of healing, or the enhancement of health, are assured. Their's is not in any way an unreasonable expectation, our lack of involvement in 
fulfilling that expectation is.

There are adequate science and technologies presently available for the botanical, chemical, and biological standardization of traditional medicines and phytotherapeutical

products. For most countries of the world, however, these technologies are known, but not fully developed, and the capacity to fully implement them as applied to their own high priority traditional medicine practices is not present. Sponsored programs are therefore needed to systematically establish safety and efficacy through multidisciplinary, international collaborative research programs. Such programs are critical for the future health of the Earth in order to begin to restore the balance of health beneficial plant and human use.

Perhaps in other eras, there were times when there was a cry that all is not well and that it was a time to step back and reflect and consider this world and the impact we are having upon our descendants' future. It is not for us to say, other than to indicate that our knowledge of our impact is more available, more visible, and more widely known now than ever before. We see the use of our natural resources as being wildly out of balance. Here, we have focused on a single aspect, the use of our natural resources for healing and health maintenance. We have seen how there is a desperate need for innovative strategies for the Natural Product Sciences to restore a balance in order to sustain the supplies of food and health care products. Now is the time for a shift in the natural product sciences community towards a greater public health policy and political involvement in how natural products are used in a societally responsible manner for globally beneficent uses.

\section{References}

1. Cordell, G.A.; Colvard, M.D. J. Ethnopharmacol. 2005, 100, 5-14.

2. Colvard, M.D.; Cordell, G.A.; Villalobos. R.; Sanchos, G.; Soejarto, D.D.; Pestle, W.; Lobo Echeverri, T.; Perkowitz, K.M.; Michel, M. J. Ethnopharmacol., 2006, In press.

3. Cordell, G.A. In: Proceedings of the 2nd International Conference and Exposition on the Modernization of Traditional Chinese Medicine, Chengdu, People's Republic of China, 2005; pp 405-418.

4. Cordell, G.A. Phytochemistry 1995, 40, 1585-1612.

5. Cordell, G.A. Phytochemistry 2000, 55, 463-480.

6. Cordell, G.A. Rev. Quim. 2002, 16, 5-12.

7. Cordell, G.A. Phytochem. Revs. 2002, 1, 261-273.

8. Cordell, G.A. Rev. Quim. 2003, 17, 3-15.

9. Cordell, G.A. Rev. Quim. 2004, 19, 33-41.

10. Cordell, G.A. Thai J. Health Res. 2004, 18, 87-105.

11. United Nations, Millennium Ecosystem Assessment. New York, NY, May, pp. 219; available at www.millenniumassessment.org. 
12. United States Census Bureau, Washington, DC, May, 2005; available at http://www.census.gov/ipc/www/img/worldpop.gif

13. United States Census Bureau, Washington, DC, May, 2005; available at http://www.census.gov/cgi-bin/ipc/popclockw

14. Reid, W.V.; Sittenfeld, A.; Laird, S.A.; Janzen, D.H.; Meyer, C.A.; Gollin, M.A.; Gomez, R.; Juma, C. Eds.; Biodiversity Prospecting. World Resources Institute: Baltimore, MD, 1993; pp 341.

15. Anonymous, Peak Oil, May, 2005; available at www.peakoil.org.

16. Anonymous, Institute for the Analysis of Global Security: Washington, DC, 2005; available at www.iags.org/futureofoil.html.

17. Campbell, C.J. Hubbert Center Newslett. July, 2002, 1-8.

18. Farnsworth, N.R.; Morris, R.W. J. Pharm. Sci. 1976, 147, 46-52.

19. Fabricant, D.S.; Farnsworth, N.R. Environ. Hlth. Persp. 2001, 109, (Suppl. 1), 69-75.

20. Farnsworth, N.R.; Akerele, O.; Bingel, A.S.; Soejarto, D.D.; Guo, Z. 1985. Bull. World Hlth. Org. 1985, 63, 965-981.

21. Newman, D.J.; Cragg., G.M.; Snader, K.M. J. Nat. Prod. 2003, 66, 1022-1037.

22. McCoy, M.; Jarvis, L.M. Chem. Eng. News April 10, 2006; p 19 et seq.

23. Mullin, R. Chem. \& Eng. News 2006, June 19, 30-55.

24. Moses, III, H.; Dorsey, A.R.; Matheson, A.H.M.; Thier, S.O. JAMA 2005, 294, 1333-1342.

25. Di Masi, J.A.; Hansen, R.W.; Grabowski, H.G. J. Hlth. Econ. 2003, 22, 151-185.

26. Hileman, B. Chem. \& Eng. News 2006, June 19, 80-99.

27. Borman, S. Chem. \& Eng. News 2006, June 19, 56-78

28. Malcolm, J.R.; Liu, C.; Neilson, R.P.' Hansen, L.; Hannah, L. Conserv. Biol. 2006, 20, 538-548.

29. Buss, A.D.; Cox, B.; Waigh, R.D. In: Burger's Medicinal Chemistry and Drug Discovery. Sixth Ed;; Abraham, D.J. Ed.; John Wiley \& Sons, Inc.: New York, NY, 2003; Vol. 1, p 847-900.

30. Center for Budget and Policies, August, 2005; data from the website www.cbpp.org/8-30-05health.htm

31. Anonymous, World Health Organization, Geneva, Switzerland, 2000; available at www.who.int/inf-pr-2000/en/pr2000-42.html

32. Anonymous, World Health Organization, Geneva, Switzerland, 2006; available at www.who.int/csr/disease/avian influenza/country/ cases table 2006_06 20/en/index.html

33. Anonymous, World Health Organization, Geneva, Switzerland, 2004; available at www.who.int/csr/sars/country/table2004 04 21/en/index.html

34. Cragg, G.M.; Newman, D.J.; Snader, K.M. J. Nat. Prod. 1997, 60, 52-60.

35. Cordell, G.A.; Quinn-Beattie, M.L.; Farnsworth, N.R. Phytother. Res. 2001, 15, 183-205.

36. Lovelock, J.E. Gaia A New Look at Life on Earth; Oxford University Press: Oxford, 1979; pp 157.

37. Wackernagel, M., N. B. Schulz, and D. Deumling. et al. Proc. Natl. Acad. Sci. USA 2001, 
99, 9266-9271.

38. Cordell, G.A.; Beecher, C.W.W.; Kinghorn, A.D.; Pezzuto, J.M.; Constant, H.L.; Fang, L.; Seo, E.K.; Long, L.; Cui, B.L.; Barrilos, K.S. In: Studies in Natural Products Chemistry, Atta-ur-Rahman, Ed.; Elsevier Science Publishers: Amsterdam, 1997; Vol. 19, p 749-791.

39. Cordell, G.A.; Shin, Y.G. Pure Appl. Chem. 1999, 71, 1089-1094.

40. Naoshima, Y.; Akakabe, Y. Phytochemistry 1993, 30, 3595-3597.

41. Sousa, J.S.N.; Machado, L.L.; de Mattos, M.C.; Solange, S.; Lemos, T.L.G.; Cordell, G.A. Phytochemistry, 2006, 67, 1637-1643. 